\title{
correspondence
}

\section{LEPRA'S money}

SIR, - In writing on leprosy (March 20), Dr Crawford claims that the numbers on treatment have remained low for the reasons he mentions and not for lack of money, as LEPRA claims.

The cost of maintaining patients in institutions is enormously high and LEPRA recognised this in 1963 when it carried out a reappraisal of its work. Consequently it has not for many years given grants for maintaining patients unnecessarily in institutions, but still maintains that the numbers on treatment have remained low because of a lack of money, as the cost of finding patients and ensuring their regular treatment on a domiciliary basis for at least three years is very high.

Dr Crawford concludes his article with an accurate example of how LEPRA is using a very small proportion of the money given to it, for a specific purpose. His example, however, may have given your readers an inaccurate picture since the example suggests that voluntary agencies in Europe are still spending most of their income on institutional care. This is not the case with LEPRA since its contribution to the fight against leprosy in 1974 was: - $£ 210,000$ on leprosy control projects, mainly for domiciliary treatment.

- $£ 66,000$ on grants to encourage early diagnosis for domiciliary treatment of children suffering from leprosy.

- $£ 10,500$ on leprosy research.

- $£ 6,600$ on training.

- $£ 6,500$ on the leprosy aspect of multipurpose rural health projects.

\section{LEPRA, Colchester, UK}

\section{G. F. HARRIS}

\section{HTRs, zink and aluminium}

SIR,-The high temperature gascooled reactor (HTR) has frequently been suggested as a source of process heat for steel-making, but we suggest that it could also be used in the zinc -and aluminium-making processes. The key step is the reduction of zinc oxide using a gas heated by an HTR.

At present there are two principal techniques involved in the zincmaking process: chemical reduction using coal, and electrolysis of zinc oxide. The first is carried out at temperatures of $1,200-1,400{ }^{\circ} \mathrm{C}$ and needs a correspondingly large supply of coke to provide these high temperatures. Zinc oxide might, however, conveniently be reduced using methane or hydrogen with an HTR as the source of process heat. In this case temperatures much below $1,000{ }^{\circ} \mathrm{C}$ are necessary-and these can be delivered by today's HTR technology. Natural gas or methane produced by coal gasification using HTR process heat can then be heated by the HTR to $800{ }^{\circ} \mathrm{C}$ and can be used for the reduction of zinc oxide. If this reduction has to be done with hydrogen, the latter might be produced by steam reforming of methane or water splitting, using process heat.

The zinc metal produced can either be sold or used in the aluminiummaking process. Aluminium is at present produced by molten-salt electrolysis of alumina but high electrical energy requirements and high investment costs are disadvantages of this method. A new purely chemical reduction method, the socalled Toth process, seems to avoid these drawbacks. It is based on a four-step process in which aluminium metal is obtained from an ore containing alumina by way of aluminium chloride. Aluminium chloride is reduced with manganese metal yielding an aluminium-manganese alloy and manganese chloride, which is subsequently oxidised with air and finally reduced with coke at $1,750{ }^{\circ} \mathrm{C}$.

Zinc might be used instead as reducing metal. In contrast to manganese oxide, the zinc oxide formed can be reduced by hydrogen or methane at temperatures far below $1,000{ }^{\circ} \mathrm{C}$.

S. Huwyler \& W. Seifritz Würenlingen, Switzerland

\section{Nitrogen fixation}

SIR,-Does A. B. Lovins (May 1) really believe that those working on nitrogen fixatioi have not tried to imagine what would happen if they succeeded "beyond one's wildest dreams"?

What if one did develop universal nitrogen-fixing systems for plant life on this planet? The effect would be the same as if adequate conventional nitrogenous fertiliser were universally available: light, water, nutrients other than $\mathrm{N}$ (K, P, S, Co, Mo and so on) would become limiting, depending on the particular environments. Assuming all these deficiencies could be corrected artificially, $\mathrm{CO}_{2}$ fixation -would be the final limiting factor-as it is in advanced agricultural industry already.

The ecological and environmental effects would be just about the same as the use of nitrogenous fertiliser has entrained already, but the drain on the world's energy resources (for fertiliser production) would certainly be very much less. The pollution problem arising from run-off might also be lessened, though not eliminated-rotting legumes produce a run-off problem even today. In compensation, a few hundred million people on this planet would be better nourished and a few hundred thousand would be saved from death by starvation each year. They would, of course, increase and multiply, so a global problem would be augmented and its solution postponed rather than solved. Yet some feel that there are better ways of tackling the population problem than by accepting starvation.

University of Sussex, UK John Postgate

\section{Ohta and evolution}

Sir,- The paper by Ohta (November 29) on which my comments (April 3) have so displeased Nigel Calder (May 1), appeared under the rubric of "Review Article", which might lead the uninitiated (including perhaps $\mathrm{Mr}$ Calder) to expect a more or less scholarly summary of recent evidence and theories. What Ohta gave us, in fact, was a highly partisan presentation of the case for one side only on a controversial issue.

My remarks on statistics were perhaps open to misunderstanding; it was not intended to imply that statistical methods have no place in evolutionary studies-for example the statistical work of R. A. Fisher was a very important contribution to the theory of natural selection-but merely to point out that, in the macroscopic world at least, the appeal to chance is essentially an argument from ignorance, and should not be made until causal explanations have been clearly shown to fail.

$\mathrm{Mr}$ Calder's reference to my remarks on scientific truths makes it clear that there are philosophical differences between us which would need more space for their discussion than this letter could afford. To quote a writer for whom Nigel Calder might have more respect than for the scriptures, William Blake wrote that "establishment of truth depends on destruction of falsehood continually" - in that spirit I was moved to express my criticism rather more forcefully than is usual in these columns.

R. A. Crowson

University of Glasgow, UK 